\title{
A Comparative Study of Management of Supracondylar Fracture of Humerus in Children by Two Techniques
}

\author{
Rajneesh Jindal ${ }^{1 *}$, Neera Jindal ${ }^{1}$, Ankur Dass ${ }^{2}$ \\ ${ }^{1}$ Associate Professor, ${ }^{2}$ Assistant Professor, \\ Department of Orthopaedics, Mayo Institute of Medical Sciences, Barabanki, U., India.
}

\begin{abstract}
Background: Supracondylar humerus fractures in children are very common. The present study aimed in comparing the two techniques of management of supracondylar humerus fracture in children.

Materials \& Methods: This prospective study was conducted in the department of orthopaedics in 2014. It included 52 cases with closed Gartland type 3 fractures. Patients were divided into 2 groups. Group I- includes 26 patients which were operated by closed pinning method under short general anaesthesia. Group II- includes 26 patients which were operated by open pinning method under general anaesthesia with intubation.

Results: Out of 52 patients, 26 are in group I and 26 are in group II. Both group included equal (13) numbers of male and females. Reason for fracture was fall from bicycle (20), fall from tree (7) and fall while playing (25). The difference was statistical significant. Excellent results were found in 14 patients in group I and 8 patients in group II. Good results were seen in 6 patients in group I and 7 patients in group II. 4 patients in group I and 5 patients in group II showed fair results. 2 and 6 patients showed poor results in group I and II
\end{abstract}

\section{INTRODUCTION}

Supracondylar humerus fractures in children account for $60 \%$ cases in elbow. Incidence is more in patients less than 10 years and decreases drastically as the age advances. Extension type is more common than flexion type. It is caused by fall on the outstretched hand with elbow joint in hyperextension, thus pushing the distal fragment posteriorly. ${ }^{1}$

The supracondylar fracture of humerus demand great respect in treatment because if it is not treated properly it may give rise to many complications such as Volkmann's ischemic contracture, neurovascular injury, myositis ossificans, stiffness of elbow and malunion. ${ }^{2}$

Various modalities of treatment have been proposed for the treatment of displaced supracondylar fractures of the humerus in children, such as closed reduction and plaster of paris slab application, skin traction, overhead skeletal traction, closed reduction and percutaneous pin fixation and open reduction with internal fixation. ${ }^{3}$ Displaced supracondylar fractures of humerus in children have always posed a challenge to the surgeons. Closed reduction with splint or cast immobilization and treatment with respectively. The procedure time and discharge time was less in group I as compared to group II.

Conclusion: Closed reduction with $\mathrm{K}$ wire fixation has better results as compared to open reduction and $\mathrm{K}$ wire fixation.

Key Words: Closed pinning, Open pinning, General anaesthesia, Supracondylar humerus fractures.

*Correspondence to:
Dr. Rajneesh Jindal,
Associate Professor,
Department of Orthopaedics,
Mayo Institute of Medical Sciences, Barabanki, UP, India.
Article History:
\begin{tabular}{|l|l|}
\hline \multicolumn{2}{|c|}{ Received: 28-09-2016, Revised: $16-10-2016$, Accepted: 02-11-2016 } \\
\hline $\begin{array}{l}\text { Website: } \\
\text { www.jmmrp.com }\end{array}$ \\
\hline $\begin{array}{l}\text { Dol: } \\
\text { 10.21276/ijmrp.2016.2.6.018 }\end{array}$
\end{tabular}

traction has traditionally been recommended for displaced supracondylar fractures, but difficulty in reduction, loss of reduction postoperatively or during follow-up leads to malunion and elbow stiffness. ${ }^{4}$

The present study was conducted to compare Gartland type 3 supracondylar fracture in children treated by 2 methods-Closed reduction and pinning and Open reduction and pinning.

\section{MATERIALS \& METHODS}

This prospective study was conducted in the department of orthopaedics in 2014. It included 52 cases with closed Gartland type 3 fractures. Patients were divided into 2 groups.

Group I: Includes 26 patients which were operated by closed pinning method under short general anaesthesia.

Group II: Includes 26 patients which were operated by open pinning method under general anaesthesia with intubation.

Closed reduction was attempted under i.v sedation to prevent neurovascular compromise followed by radiographs to assess reduction of fracture and to assess chest in every patient. 
$\mathrm{K}$ wires of various diameter ranging from 1.5 to $2 \mathrm{~mm}$ were used. In group I, closed reduction was done and fracture was fixed with either $2 \mathrm{k}$ wires one from each condyle with an angle of 30 to 40 degrees with humeral shaft and 10 degree posteriorly or with $2 \mathrm{k}$ wires from lateral condyle. The $k$ wires were removed after 3 weeks.

In Group 2 patients, fracture was reduced with traction and clamps. Fixation was done with $\mathrm{k}$ wires. $\mathrm{K}$ wires were removed at 3 weeks and slab continued for 1 more week. Patients were on follow up, and the following points were noted: Clinical-range of motion, change in carrying angle, neurovascular problems, and wound complications. Results obtained were subjected to statistical analysis. Chi - square test was used. $P$ value less than 0.05 was considered significant.

Table I: Distribution of Patients in Both Groups

\begin{tabular}{lcccc}
\hline \multicolumn{5}{c}{ TOTAL -52} \\
\hline GROUP & \multicolumn{3}{c}{ GROUP I (26) } & GROUP II (26) \\
GENDER & MALE & FEMALE & MALE & FEMALE \\
NO. & 13 & 13 & 13 & 13 \\
\hline
\end{tabular}

Table II: Patients Response Based On FLYNN'S 5 Grading

\begin{tabular}{lccc}
\hline GRADE & GROUP I & GROUP II & P VALUE \\
\hline EXCELLENT & 14 & 8 & 0.02 \\
GOOD & 6 & 7 & \\
FAIR & 4 & 5 & \\
POOR & 2 & 6 & \\
\hline
\end{tabular}

Table III: Procedure Time \& Discharge Time In Both Groups

\begin{tabular}{lccc}
\hline & GROUP I & GROUP II & PVALUE \\
\hline PROCEDURE TIME & 25 MINUTES & 70 MINUTES & 0.001 \\
DISCHARGE TIME & 1ST DAY & 5 & 0.01 \\
\hline
\end{tabular}

\section{RESULTS}

Table I shows that out of 52 patients, 26 are in group I and 26 are in group II. Both group included equal (13) numbers of male and females.

Graph I shows that out of 52 patients, 30 ranged from 3-5 years, 10 ranged from 8-12 years and 12 ranged from $13-15$ years of age. There was statistical significant difference in number of patients in different age group.

Graph II shows that reason for fracture was fall from bicycle (20), fall from tree (7) and fall while playing (25). The difference was statistical significant.
Table II shows excellent results were found in 14 patients in group I and 8 patients in group II. Good results were seen in 6 patients in group I and 7 patients in group II. 4 patients in group I and 5 patients in group II showed fair results. 2 and 6 patients showed poor results in group I and II respectively. The difference was statistical significant.

Table III shows that in group I, procedure time was 25 minutes and in group II 70 minutes. The discharge time in group I and II was $1^{\text {st }}$ day and $5^{\text {th }}$ day respectively. The difference was highly significant.

\section{Graph I: Age Wise Distribution Of Patients}

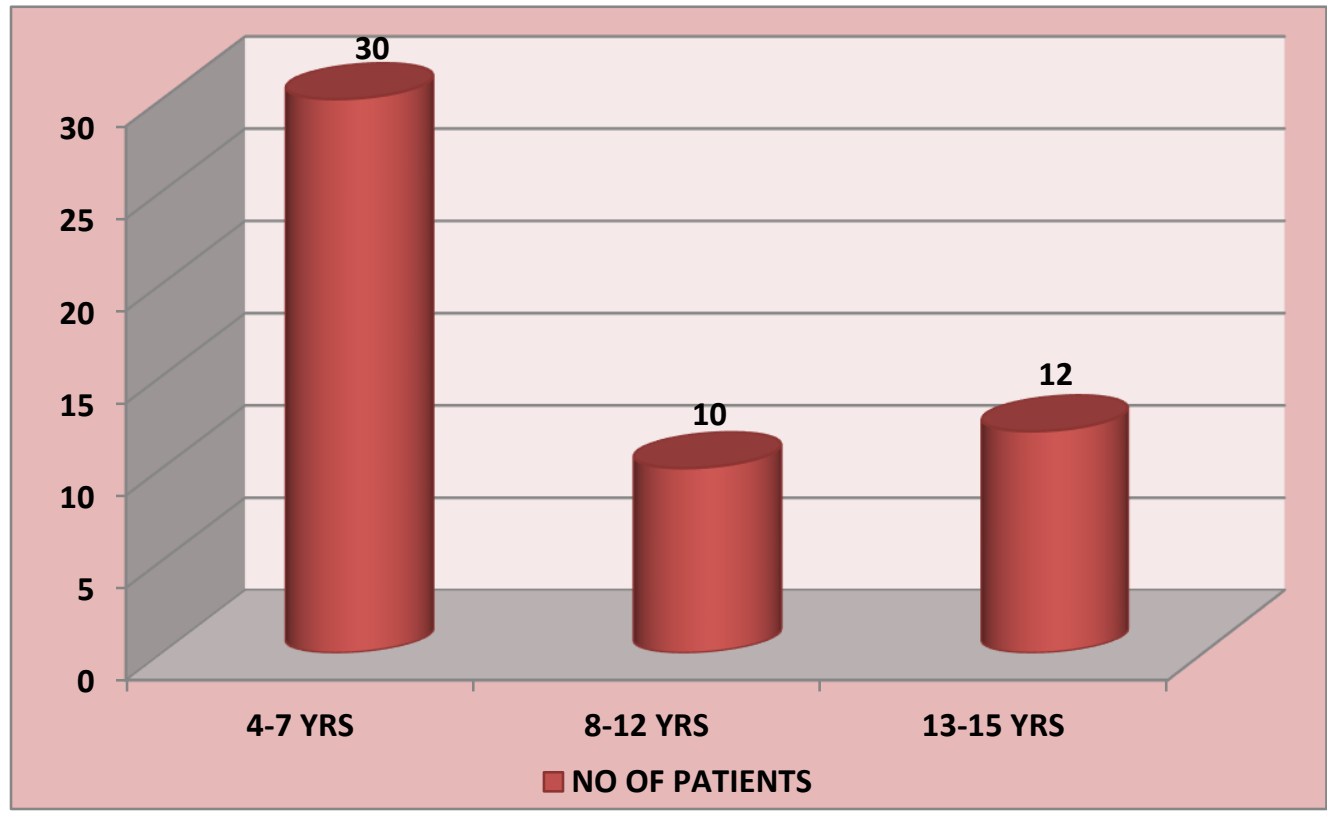


Graph II: Distribution Of Patients Based On Etiology

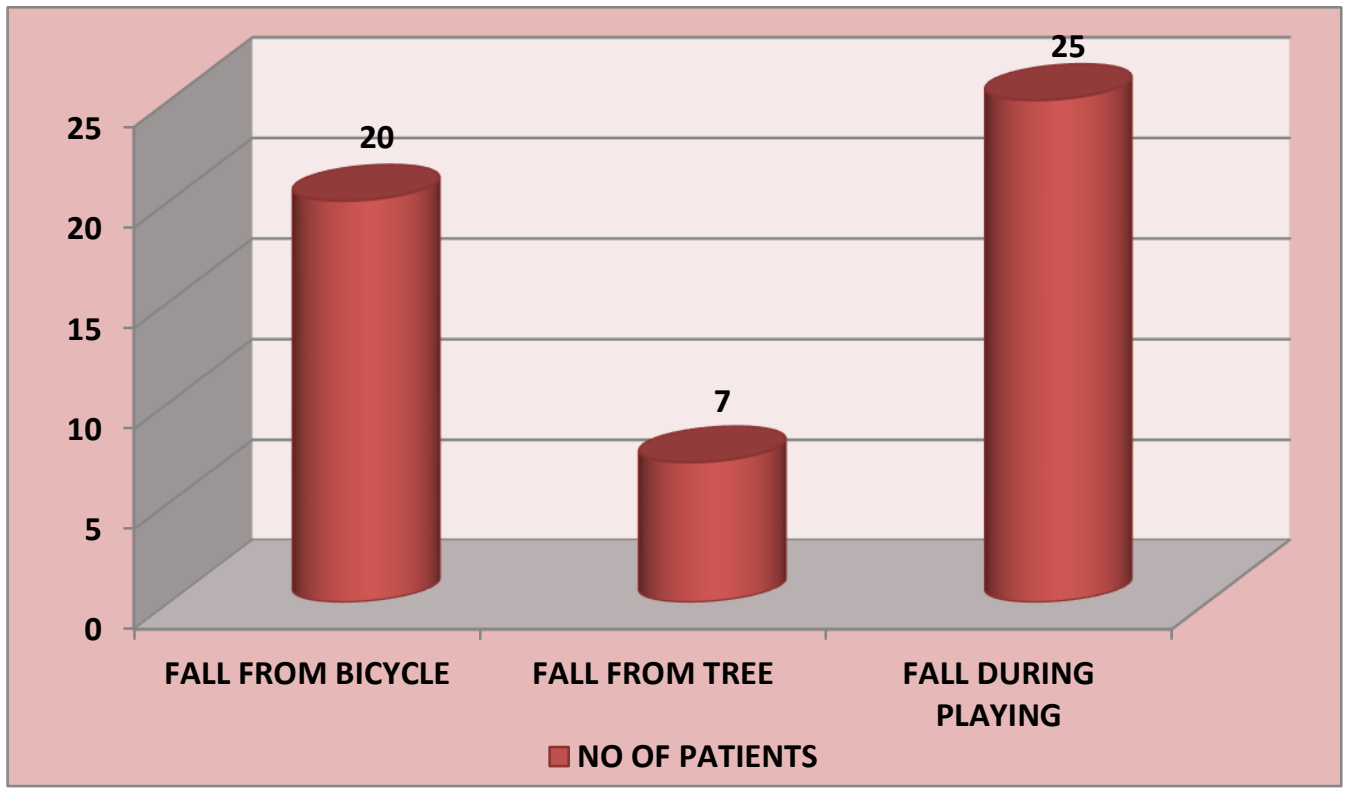

\section{DISCUSSION}

Supracondylar fracture of humerus is the commonest injury around elbow in children. It demands great respect in treatment because if it is not treated properly, it may give rise to neurovascular compromise, difficulty in obtaining or maintaining reduction and poor late results because of stiffness of elbow or malunion. ${ }^{6}$ Most frequently used methods of treatment are closed reduction and application of cast, skeletal traction, closed reduction and percutaneous K-wire fixation and open reduction and internal fixation with K-wires. ${ }^{7}$ The present study included 52 children. They were divided into group I and group II. In group I, closed reduction and $\mathrm{K}$ wire fixation was done and in group II, open reduction and internal fixation with $\mathrm{K}$ wire was done.

Out of 52 patients, 30 ranged from 3-5 years, 10 ranged from 8-12 years and 12 ranged from 13- 15 years of age. Reason for fracture was fall from bicycle (20), fall from tree (7) and fall while playing (25). Mehserle ${ }^{8}$ in his study also found fracture resulting from playing as a main reason of humerus fracture.

Results in both groups were compared by flynn's grading. Excellent results were found in 14 patients in group I and 8 patients in group II. Good results were seen in 6 patients in group I and 7 patients in group II. 4 patients in group I and 5 patients in group II showed fair results. 2 and 6 patients showed poor results in group I and II respectively.

Holmberg 9 in his study found $56 \%$ excellent/ good result and in our study it was $76 \%$ in group 1 and $57 \%$ in group 2 . Kurer and Regan ${ }^{10}$ had $62.9 \%$ excellent/ good results. Gruber and Hudson ${ }^{11}$ had $65.3 \%$ excellent/ good results.

\section{CONCLUSION}

Author concluded that the procedure time and discharge time was less in group I as compared to group II. Thus, closed reduction with $\mathrm{K}$ wire fixation has better results as compared to open reduction and $\mathrm{K}$ wire fixation.

\section{REFERENCES}

1. Aronson DC, van Vollenhoven E, Meeuwis JD. K-wire fixation of supracondylar humeral fractures in children: results of open reduction via a ventral approach in comparison with closed treatment. Injury 1993; 24: 179-181.
2. Farnsworth CL, Silva PD, Mubarak SJ. Etiology of supra-condylar humerus fractures. J Pediatr Orthop. 1998;18:38-42.

3. Boyd DW, Aronson DD. Supracondylar fractures of the humerus: a prospective study of percutaneous pinning. J Pediatr Orthop. 1992; 12:789-794.

4. Yadav UB, Singhal R, Tonk G, Aggarwal T and Verma AN. Crossed pin fixation in displaced supracondylar humerus fractures in children. Traumatology. 2004; $38: 166-169$.

5. Flynn JC, Matthews JG, Benoit RL. Blind pinning of displaced supracondylar fractures of the humerus in children. Sixteen years' experience with long-term followup. J Bone Joint Surg Am. 1974; 56:263-272.

6. Sial NA, Yasin A and Rashid A. Supracondylar humerus fractures outcome of open reduction and percutaneous crossed pin fixation. Prof Med J. 2011; 18: 147-153.

7. Pirone AM, Graham HK, Krajbich Jl. Management of displaced extension-type supracondylar fractures of the humerus in children. $\mathrm{J}$ Bone Joint Surg Am. 1988; 70: 641-50.

8. Mehserle WL, Meehan PL. Treatment of the displaced supracondylar fracture of the humerus (type III) with closed reduction and percutaneous cross-pin fixation. JPediatr Orthop.1991;11:705-11. 9. Holmberg L. Fractures of the distal end of the humerus in children. Acta Chir Scand. 1945; 103: 1-7.

10. Kurer MH, Regan MW. Completely displaced supracondylar fracture of the humerus in children. A review of 1708 comparable cases. Clin Orthop Relat Res. 1990; 256: 205-214.

11. Gruber MA, Hudson OC. Supracondylar fracture of the humerus in childhood. End result study of open reduction. J Bone Joint Surg Am. 1964; 46:1245-1252.

Source of Support: Nil. Conflict of Interest: None Declared. Copyright: (c) the author(s) and publisher. IJMRP is an official publication of Ibn Sina Academy of Medieval Medicine \& Sciences, registered in 2001 under Indian Trusts Act, 1882. This is an open access article distributed under the terms of the Creative Commons Attribution Non-commercial License, which permits unrestricted noncommercial use, distribution, and reproduction in any medium, provided the original work is properly cited.

Cite this article as: Rajneesh Jindal, Neera Jindal, Ankur Dass. A Comparative Study of Management of Supracondylar Fracture of Humerus in Children by Two Techniques. Int J Med Res Prof. 2016; 2(6):95-97. DOI:10.21276/ijmrp.2016.2.6.018 